\title{
Research on Improving Patients' Insulin Self-care Ability based on Swanson Care Theory
}

\author{
He Zilin ${ }^{1}$ and Wang Ruyi ${ }^{2}$ \\ ${ }^{1,2}$ Hohai University, China \\ 1368904587@qq.com
}

\begin{abstract}
In recent years, as the number of diabetic patients has gradually increased, the number of insulin injections has also increased accordingly. The mastery of self-injection of insulin by diabetics is essential to the patient's recovery. Therefore, it is necessary to carry out effective insulin self-care ability improvement education for patients, so that patients can better master self-care skills. This article discusses how to improve patients' insulin self-care ability based on Swanson's care theory. The sample used 130 type 2 diabetic patients and set up the control group and the observation group respectively. Patients in the control group used traditional self-care education methods. The observation group used Swanson-based self-care education methods. Use questionnaires to analyze experimental results. The results showed that the selfcare ability score of the observation group was significantly higher than the self-care ability score of the control group 2 months after discharge, indicating that the Swanson care theory can effectively improve the insulin self-care ability of patients, thereby improving the health of the people.
\end{abstract}

Keywords: Insulin, Self-care, Swanson care theory

\section{Introduction}

In recent years, with the increasing prevalence of diabetes, the number of insulin injection patients is also increasing year by year. Insulin therapy is an important means to control hyperglycemia. Insulin therapy may be the most important and even necessary blood glucose control measure when the course of the disease is longer [1]. Insulin injection is the key step. Domestic researchers found that the technical level of self-injection of insulin in diabetic patients in China needs to be improved, and there is a general lack of relevant knowledge [2][3].

Irregular injection behavior not only affects the rate of blood glucose compliance but also causes a series of complications such as subcutaneous induration, bleeding, and infection at the injection site. Studies have found that irregular injection techniques lead to insulin allergic reactions. This shows that it is imperative to strengthen standardized and comprehensive health education for patients using insulin. The lack of confidence in self-management in diabetic patients can lead to decreased compliance with insulin therapy [4]. Helping patients obtain good social and emotional support, strengthening self-management and health education will help reduce their psychological resistance to insulin therapy [5].

Article history:

Received (May 28, 2020), Review Result (July 5, 2020), Accepted (August 9, 2020) 
The Swanson care theory is proposed by Dr. Swanson. The Swanson care theory is based on the perspectives of the carer and the cared. It points out that care is wise to care. Its goal is to promote the health and independence of patients. It breaks down care into "Knowing, Being with, Doing for, Enabling, Maintaining belief" in the 5 processes.

This theory focuses on the importance of the emotional level of patients and encourages nurses to evaluate and understand this level to promote the mental health of patients [6][7]. The theory believes that the professional care of nurses is mainly reflected in the above five care processes. At the same time, this theory can provide a guiding framework for nursing practice, with specific and clear guidance, so that nursing behavior can be implemented. Domestic researchers have applied the Swanson caring theory to health promotion and education to promote the lactation of parturients, increase their breastfeeding rate after delivery, and effectively improve the anxiety and tension of parturients [8]. In this study, Swanson's care theory was applied to insulin injection education for diabetic patients with effective results.

\section{Materials and methods}

\subsection{Clinical data}

Using convenience sampling, 120 patients with type 2 diabetes who were hospitalized between March to December 2018 were selected.

Inclusion criteria:

(1) Meet the diagnostic criteria for type 2 diabetes recommended by the WHO in 1999.

(2) Have not used insulin in the past.

(3) Need to continue to use insulin injections after this discharge.

(4) Have complete cognitive and behavioral abilities.

Exclusion criteria:

(1) Insulin injection by others.

(2) Incomplete data collection.

According to the chronological order, 56 patients admitted from March to July of 2018 were set as the control group, and 64 patients admitted from August to December 2018 were set as the observation group. This study was approved by the hospital ethics committee, and all patients and their families were informed and signed informed consent. The two groups of patients had no statistically significant differences in gender, age, course of the disease, etc. (all $\mathrm{P}>0.05$ ), and they were comparable, see [Table 1].

Table 1. Comparison of general data of diabetic patients in two groups $(\bar{x} \pm s)$

\begin{tabular}{|c|c|c|c|c|c|c|c|c|c|c|c|c|c|}
\hline \multirow{2}{*}{ Group } & \multirow{2}{*}{$\begin{array}{c}\text { Cas } \\
\text { es }\end{array}$} & \multicolumn{2}{|c|}{ Gender } & \multirow{2}{*}{ Age } & \multirow{2}{*}{$\begin{array}{c}\text { Course } \\
\text { of } \\
\text { disease }\end{array}$} & \multirow{2}{*}{$\begin{array}{c}\text { Numbe } \\
\text { r of } \\
\text { injectio } \\
\text { ns per } \\
\text { day }\end{array}$} & \multicolumn{3}{|c|}{ Payment method } & \multicolumn{4}{|c|}{ Education level } \\
\hline & & Male & $\begin{array}{c}\text { Femal } \\
\mathrm{e}\end{array}$ & & & & $\begin{array}{l}\text { Medical } \\
\text { Insurance }\end{array}$ & $\begin{array}{c}\text { Insuran } \\
\text { ce }\end{array}$ & $\begin{array}{c}\text { Own } \\
\text { expense }\end{array}$ & $\begin{array}{c}\text { Primary } \\
\text { school }\end{array}$ & $\begin{array}{c}\text { Junio } \\
\text { r } \\
\text { scho } \\
\text { ol } \\
\end{array}$ & $\begin{array}{c}\text { High } \\
\text { school }\end{array}$ & $\begin{array}{c}\text { Universit } \\
\mathrm{y} \text { and } \\
\text { above }\end{array}$ \\
\hline $\begin{array}{c}\text { Observe } \\
\text { group }\end{array}$ & 64 & 34 & 30 & $\begin{array}{c}57.13 \pm \\
9.34\end{array}$ & $\begin{array}{c}7.66 \pm \\
5.24\end{array}$ & $\begin{array}{c}2.92 \pm \\
0.76\end{array}$ & 57 & 1 & 6 & 15 & 17 & 21 & 11 \\
\hline Statistic & \multicolumn{3}{|c|}{$0.022 \mathrm{a}$} & $0.067 \mathrm{~b}$ & $0.081 \mathrm{~b}$ & $-0.420 b$ & \multicolumn{3}{|c|}{$1.477 \mathrm{a}$} & \multicolumn{4}{|c|}{$0.148 \mathrm{c}$} \\
\hline$P$ value & \multicolumn{3}{|c|}{0.884} & 0.947 & 0.936 & 0.676 & \multicolumn{3}{|c|}{0.843} & \multicolumn{4}{|c|}{0.883} \\
\hline
\end{tabular}

Note: $a$ is the $\chi^{2}$ value, $b$ is the $t$ value, $c$ is the $Z$ value 


\subsection{Nursing methods}

\subsubsection{Control group}

The conventional nursing education model is adopted. During the patients' hospitalization, they participated in two intensive courses taught by a diabetes specialist nurse, including diabetes diet, exercise, monitoring, and prevention of complications. Participates in the insulin injection workshop: Diabetes specialist nurses made PPT to teach insulin-related knowledge according to the 2016 edition of the Chinese Diabetes Drug Injection Technical Guide. Watch the "Diabetes Drug Specifications" produced by the Diabetes Branch of the Chinese Medical Association and the Diabetes Teaching and Management Group Nine Steps of Injection Video [9][10]. Diabetes specialist nurses demonstrate the operation of the insulin pen, and the patients follow along with the injection exercises. Insulin education brochures and insulin injection site rotation cards are issued. When the patient is discharged from the hospital, the nurse will provide evaluation and guidance. Telephone follow-up 8-14 days after discharge. Three months after discharge, come to the hospital's endocrinology outpatient clinic to review fasting blood glucose, $2 \mathrm{~h}$ postprandial blood glucose, and glycosylated hemoglobin (HbAlc), and complete the investigation by a diabetes specialist nurse at the diabetes education clinic.

\subsubsection{Observation group}

Based on routine nursing education in the control group, the Swanson care theory was used for nursing care. The details are as follows.

(1) Knowing

Nurses should strive to understand the meaning of events in the life of the individual, avoid preconceived notions when understanding, focus on the individual's concerns and true desires, constantly look for clues, and fully evaluate the individual. The doctor prescribes an insulin order, and diabetes specialist nurses go to the bedside to investigate patients through the "My Views on Insulin" questionnaire in the insulin interview kit. Fully evaluate the patients, look for clues, and explore the patient's attitude and cognition toward insulin treatment. Fully understand the patient's psychological status. Clarify the most important concerns, obstacles, and issues that patients are most concerned about.

From the survey, it is found that patients are worried that insulin will become addictive and fear that they will inject themselves. The injection will take a lot of time and energy as the main factor affecting patients' willingness to use insulin. After fully understanding the patient's psychological state, the nurses formulate targeted psychological support and nursing measures based on the actual situation.

(2) Being with

Be with the patient, share your feelings, and avoid putting pressure on the patient. Send the patient the message that "the nurse is ready and willing to serve them". Diabetes specialist nurses learn about the patient's information based on the questionnaire and grasp the key to the problem for in-depth communication. Each person will clarify the misunderstandings in insulin therapy, encourage patients to ask questions and resolve patients' doubts. Make patients agree with their beliefs and eliminate cognitive impairment of insulin. Let patients truly understand and accept the treatment plan. And according to their cultural level, acceptability and willingness, etc., work with patients to develop personalized insulin injection education plans and goals. In the process of contact between nurses and patients, 
they must have affinity and empathy in speech and body, so that they can be committed, cared and concerned by patients.

(3) Doing for

"Doing for" does not mean doing everything for the patient, let alone advocating excessive intervention. It requires nurses to provide appropriate guidance and assistance after assessing and balancing individual needs, limitations, and existing resources to promote the individual gains independence as soon as possible.

Based on the attitude of "if the individual has sufficient strength, knowledge or determination, he will help himself." By predicting the needs of the individual, providing relevant services in time, making the individual feel comfortable, and at the same time consciously maintaining the dignity of the individual.

Although patients have received insulin therapy, some patients believe that only nurses can do injections under the influence of mainstream culture. Patients feel that they can't learn injection techniques, and have hesitation, anxiety, fear, and resistance to self-injecting insulin, and they are unwilling to learn self-injection of insulin. This requires emotional and psychological help from nurses.

(a) Insulin injection workshops pay attention to personalized counseling: the diabetes specialist nurses understand each patient's biggest concerns about insulin injections through preliminary assessments and exchanges before the class, consciously guide and resolve doubts during injection exercises, and encourage patients to speak out the feeling of selfinjecting insulin and express your own opinions. Avoid accusations during practice, and encourage and praise them for every bit of progress and effort, so that patients can positively identify with themselves, thereby improving self-confidence and motivation of self-injection.

(b) Organize a group education: every Thursday afternoon, the diabetes specialist nurse organizes patient group education, and at the same time invites $2 \sim 3$ patients who have had insulin injection experience to participate, and share the problems, behavioral skills, dietary exercise cooperation, self-management experience, and lessons, channels for seeking help, psychological adjustment, etc. during insulin injection

In the process of interaction, nurses should be patient-centered, educating nurses to create a relaxed and happy atmosphere, encouraging each patient to actively express what they think, and gain positive energy through the presence of patients with the same experience, talking to each other, and encouraging each other.

(c) Watch an educational video about insulin by medical experts: Diabetes patients in China have various sources of information, but medical staff is still the most trusted source of information for patients.

In particular, the opinions of familiar and favorite experts are well accepted by patients. However, there are fewer opportunities for clinical medical experts to have face-to-face communication and education with patients. For this reason, the hot issues that are generally concern by insulin treatment patients, such as insulin addiction? Does the insulin injection indicate that you are seriously ill? Can I change my medication once insulin is on?

The doctors above the deputy director combined the treatment cases to make videos of their own opinions and viewpoints. Every Saturday from 18:00 to 18:30, the patients will be organized to watch in the classroom. By listening to the stories told by medical experts, the patients will be more accurate in insulin treatment.

(4) Enabling

Inform and explain carefully, support the patient to do what he can give positive feedback in time, cultivate the patient's confidence, make them more capable of making choices and 
decisions, improving the individual's self-care ability. On the day of the insulin workshop education, the responsible nurse or diabetes specialist nurse will go to the bedside to guide the patient to self-administer insulin injections and correct wrong behaviors in time. The nurse took the video, and the operation ended with the patient replaying the incorrect links and misunderstandings, and informing the possible problems of the wrong operation.

Patients who have been evaluated and mastered can no longer instruct injections, and those who have not mastered it can continue to self-inject under the guidance of nurses in each class, and if necessary, participate in the second insulin workshop course until the patient fully masters it.

(5) Maintaining belief

Believe and maintain the patient's self-esteem, maintain a hopeful attitude and fact-based optimism, and firmly believe that the patient can go through the transition and return to life.

Firmly believe that although it seems to be the last step, it is the basis of nursing care practice. Nurses must believe that patients can administer insulin injections by themselves and do a good job of self-management, and smoothly return to family, work, and social life.

The day before or on the day of discharge, the responsible nurse will evaluate the patient's self-injection insulin, and re-evaluate whether the patient has mastered the theory and practical operation of insulin self-injection skills. Re-instruct the shortcomings. Issue an insulin information sheet to the patient, and the evaluation nurse will confirm the relevant content of the patient has been mastered and signed in duplicate, one for the patient's preservation, one for the archive, and appointment for follow-up visits. Establish a discharge follow-up record sheet and keep a record of the issues that need to be focused on.

In 3-7 days, the responsible nurse will conduct the first telephone follow-up to ask in detail about the problems encountered during the injection operation and whether there are any adverse reactions, such as hypoglycemia, pain, bleeding, infection, allergies, etc., and give individualized guidance.

In case of non-compliance, ask the patient to explain the reason, help find alternative behaviors suitable for the patient, and conduct the second telephone follow-up again within the 8th to 14th days. If necessary, communicate with community nurses to provide on-site guidance or pass diabetes care education and solve the problems.

\subsection{Evaluation indicators}

\subsubsection{Insulin injection management ability}

The insulin injection management ability questionnaire is designed according to the 2016 edition of "Chinese Diabetes Drug Injection Technical Guide" using the Delph expert consultation method. A total of 12 items and a 5-point scoring method were adopted, the total score range is from 0 to 60 points. The higher the score, the higher the ability to manage insulin injections. According to expert evaluation, the item consistency of the questionnaire is 0.85 , and the content validity index is 0.88 . The questionnaire survey was performed in the outpatient clinic 3 months after the patient was discharged During the re-examination, first explain the filling method of the questionnaire to the patient during the investigation, and then ask them to complete the questionnaire independently according to their situation, fill out the questionnaire on the spot and take back the examination, and correct the questionable places on the spot. 


\subsubsection{Self-care behavior ability}

Studies have shown that the improvement of insulin injection skills can improve patients' self-care ability. In this study, the Diabetes Self-Care Scale (DSCS) was used to evaluate the self-care behavior ability of patients at the time of admission and 3 months after discharge.

The test-retest reliability of the scale is 0.92 , and the internal consistency test Cronbach's $\alpha$ value is 0.88 . The DSCS scale includes 6 components: diet control, regular exercise, medication compliance, blood glucose monitoring, foot care, and prevention and treatment of high and low blood sugar. In the table, a total of 26 item scales use a 5-point scoring method. The total score ranges from 0 to 130 points. The higher the score, the higher the patient's selfcare ability.

\subsubsection{Blood glucose level}

The fasting blood glucose, blood glucose $2 \mathrm{~h}$ after the meal and glycosylated hemoglobin of the two groups were compared at the time of admission and 3 months after discharge.

\subsection{Statistical methods}

Use SPSS 19.0 statistical software for data analysis and processing. Counting data is described by frequency and percentage, and comparison between groups is by $\chi^{2}$ test; grade data is by K-S test; measurement data is represented by $\bar{x} \pm s$, and comparison between groups is by cost Group t-test, matched-sample t-test was used for comparison within groups, $\mathrm{P}<0.05$ was considered statistically significant.

\section{Results}

\subsection{Comparison of insulin injection management ability}

3 months after discharge, the insulin injection management ability score of the observation group was $(54.06 \pm 2.70)$ points. The total score of the control group was $(42.64 \pm 4.84)$ points, the difference between the groups was statistically significant, and the differences between the groups for each item were statistically significant $(\mathrm{P}<0.05)$, see [Table 2].

\subsection{Comparison of self-care behavior ability scores}

There was no significant difference in the scores of diabetes self-care behavior ability between the two groups at admission $(\mathrm{P}>0.05)$. The total score of self-care behavior ability in the observation group 3 months after discharge was significantly higher than that ad admission, and the difference was statistically significant $(\mathrm{t}=19.393, \mathrm{P}<0.001)$, the total score of self-care behavior ability in the control group 3 months after discharge was significantly higher than that at admission, the difference was statistically significant $(t=6.273, \mathrm{P}<0.001), 3$ months after discharge, the observation group The total score of self-care behavior ability was significantly higher than that of the control group, and the difference was statistically significant $(\mathrm{P}<0.05)$, see [Table 3]. 
Table 2. Evaluation and comparison of insulin injection management ability in two groups of diabetic patients 3 months after discharge $(\bar{x} \pm s)$

\begin{tabular}{|c|c|c|c|c|c|c|c|c|}
\hline Group & Cases & $\begin{array}{l}\text { Inject } \\
\text { insulin } \\
\text { regularly } \\
\text { according } \\
\text { to doctor's } \\
\text { orders }\end{array}$ & $\begin{array}{l}\text { Eat on } \\
\text { time after } \\
\text { insulin } \\
\text { injection }\end{array}$ & $\begin{array}{c}\text { Vent } \\
\text { before } \\
\text { injection } \\
\text { until } \\
\text { droplets } \\
\text { appear on } \\
\text { the needle } \\
\text { tip } \\
\end{array}$ & $\begin{array}{l}\text { Check the } \\
\text { skin at the } \\
\text { injection } \\
\text { site and } \\
\text { avoid the } \\
\text { lesion } \\
\text { before } \\
\text { injection }\end{array}$ & $\begin{array}{l}\text { Rotate } \\
\text { injections } \\
\text { according } \\
\text { to the } \\
\text { location } \\
\text { and time } \\
\text { rules }\end{array}$ & \multicolumn{2}{|c|}{$\begin{array}{c}\text { Each injection is at least } \\
1 \mathrm{~cm} \text { away from the last } \\
\text { injection point }\end{array}$} \\
\hline Observation & 64 & $4.77 \pm 0.46$ & $4.69 \pm 0.56$ & $4.53 \pm 0.67$ & $4.38 \pm 0.76$ & $4.08 \pm 0.86$ & \multicolumn{2}{|c|}{$4.69 \pm 0.53$} \\
\hline Control & 56 & $4.01 \pm 0.86$ & $4.01 \pm 0.86$ & $3.38 \pm 1.01$ & $3.44 \pm 1.00$ & $2.88 \pm 0.88$ & \multicolumn{2}{|c|}{$3.18 \pm 0.81$} \\
\hline T value & & 6.015 & 5.009 & 7.532 & 5.899 & 7.582 & \multicolumn{2}{|c|}{12.194} \\
\hline $\mathrm{P}$ value & & 0.002 & $<0.001$ & $<0.001$ & $<0.001$ & $<0.001$ & \multicolumn{2}{|c|}{$<0.001$} \\
\hline Group & Cases & $\begin{array}{l}\text { Sterilize } \\
\text { with } \\
\text { alcohol } \\
\text { before } \\
\text { injection } \\
\text { and wait for } \\
\text { it to dry } \\
\text { before } \\
\text { injection }\end{array}$ & $\begin{array}{l}\text { After the } \\
\text { insulin } \\
\text { plunger is } \\
\text { pushed to } \\
\text { the } \\
\text { bottom, it } \\
\text { stays for } \\
\text { more than } \\
10 \\
\text { seconds } \\
\text { before } \\
\text { removing } \\
\text { the needle }\end{array}$ & $\begin{array}{l}\text { Needle for } \\
\text { single use }\end{array}$ & $\begin{array}{c}\text { Place the } \\
\text { used } \\
\text { needles in } \\
\text { a } \\
\text { dedicated } \\
\text { or covered } \\
\text { hard-shell } \\
\text { container }\end{array}$ & $\begin{array}{l}\text { The insulin } \\
\text { being used } \\
\text { is stored at } \\
\text { room } \\
\text { temperature } \\
\text { or taken } \\
\text { out of the } \\
\text { refrigerator } \\
\text { to rewarm } \\
\text { and } \\
\text { injected }\end{array}$ & $\begin{array}{c}\text { Store } \\
\text { unopened } \\
\text { insulin at } \\
2-8^{\circ} \mathrm{C}\end{array}$ & Total \\
\hline Observation & 64 & $4.34 \pm 0.88$ & $4.53 \pm 0.64$ & $4.45 \pm 0.71$ & $4.19 \pm 0.83$ & $4.56 \pm 0.61$ & $4.86 \pm 0.35$ & $54.06 \pm 2.70$ \\
\hline Control & 56 & $3.41 \pm 0.76$ & $3.29 \pm 0.85$ & $3.61 \pm 1.11$ & $3.05 \pm 1.07$ & $3.85 \pm 1.04$ & $4.55 \pm 0.67$ & $42.64 \pm 4.84$ \\
\hline $\mathrm{T}$ value & & 6.193 & 9.146 & 5.042 & 6.52 & 4.745 & 3.231 & 16.231 \\
\hline $\mathrm{P}$ value & & $<0.001$ & $<0.001$ & $<0.001$ & $<0.001$ & $<0.001$ & $<0.001$ & $<0.001$ \\
\hline
\end{tabular}

Table 3. Comparison of self-care behavioral ability scores of two groups of diabetic patients at admission and 3 months after discharge $(\bar{x} \pm s)$

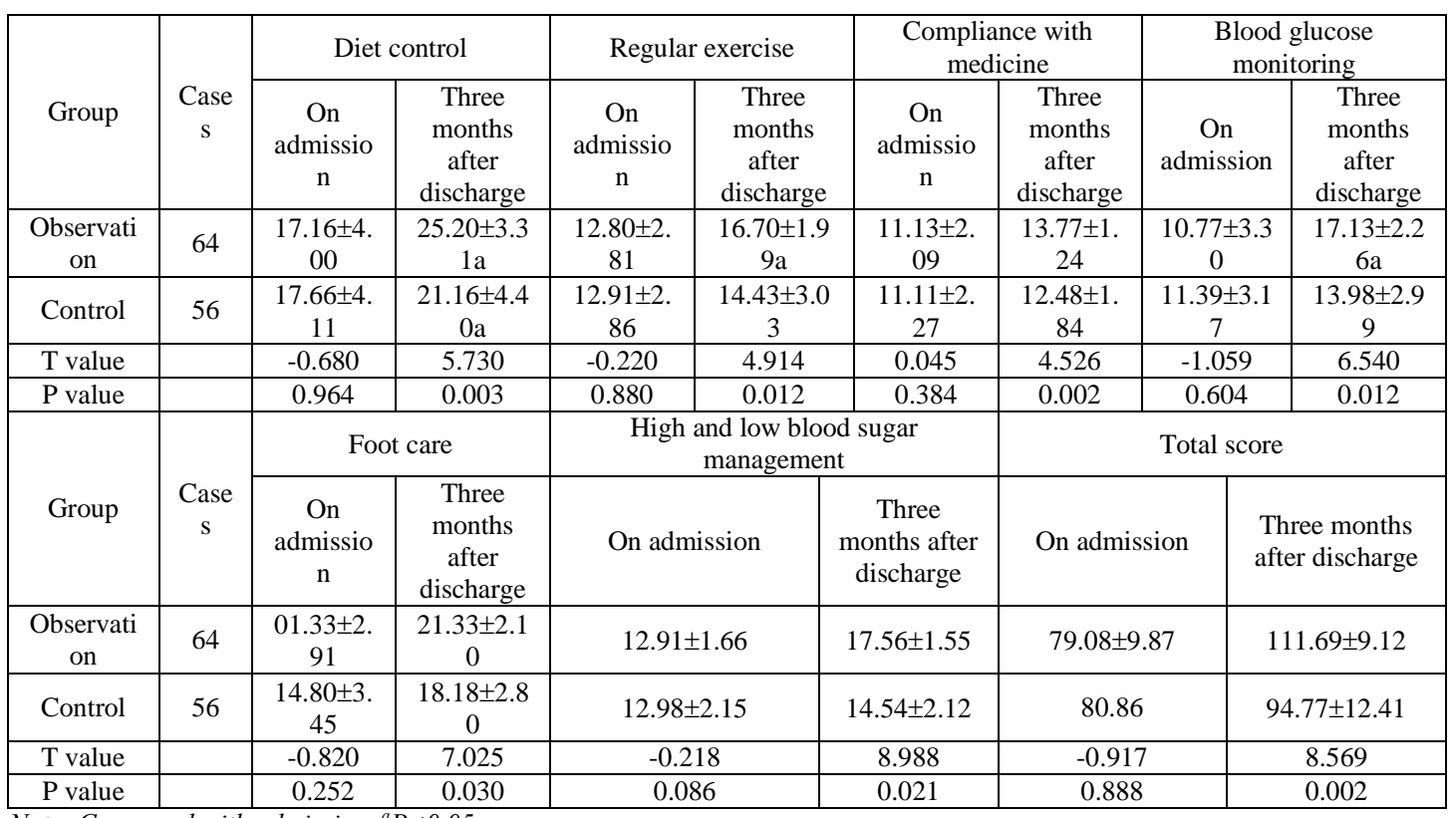

Note: Compared with admission, ${ }^{a} P<0.05$ 


\subsection{Comparison of the blood glucose levels of the two groups of patients}

The fasting blood glucose, $2 \mathrm{~h}$ postprandial blood glucose, and HbAlc of the 2 groups of patients were not statistically different at admission (all $\mathrm{P}>0.05$ ), the observation group 3 months after discharge, fasting blood glucose, postprandial. The $2 \mathrm{~h}$ blood glucose and HbAlc levels were significantly lower than those at admission, and the differences were statistically significant $(\mathrm{t}=10.339,16.178,13.91$, all $\mathrm{P}<0.001)$. The fasting blood glucose, $2 \mathrm{~h}$ postprandial blood glucose, and HbAlc levels of the control group were significantly lower than those at admission at 3 months after discharge, the difference was statistically significant $(t=7.233$, $9.497,9.776$, all $\mathrm{P}<0.001$ ). For the observation group was 3 months after discharge, the blood glucose level was better than that of the control group, and the difference was statistically significant $(\mathrm{P}<0.05)$. See [Table 4$]$ for details.

Table 4. Comparison of blood glucose levels between the two groups of diabetic patients at admission and 3 months after discharge $(\bar{x} \pm s)$

\begin{tabular}{|c|c|c|c|c|c|c|c|}
\hline \multirow{2}{*}{ Group } & \multirow{2}{*}{ Cases } & \multicolumn{2}{|c|}{ Fasting blood glucose $(\mathrm{mmol} / \mathrm{l})$} & \multicolumn{2}{|c|}{$\begin{array}{c}\text { 2h blood glucose after a } \\
\text { meal(mmol/L) }\end{array}$} & \multicolumn{2}{c|}{ HbAlc(\%) } \\
\cline { 3 - 8 } & & On admission & $\begin{array}{c}\text { Three } \\
\text { months } \\
\text { after } \\
\text { discharge }\end{array}$ & $\begin{array}{c}\text { On } \\
\text { admission }\end{array}$ & $\begin{array}{c}\text { Three months } \\
\text { after discharge }\end{array}$ & $\begin{array}{c}\text { On } \\
\text { admission }\end{array}$ & $\begin{array}{c}\text { Three } \\
\text { months } \\
\text { after } \\
\text { discharge }\end{array}$ \\
\hline Observation & 64 & $12.89 \pm 4.80$ & $6.33 \pm 1.65 \mathrm{a}$ & $19.55 \pm 5.04$ & $8.72 \pm 1.81 \mathrm{a}$ & $9.70 \pm 1.28$ & $7.06 \pm 0.80 \mathrm{a}$ \\
\hline Control & 56 & $12.34 \pm 4.20$ & $7.63 \pm 2.47 \mathrm{a}$ & $19.41 \pm 4.89$ & $11.36 \pm 4.04 \mathrm{a}$ & $9.66 \pm 1.13$ & $7.68 \pm 1.01 \mathrm{a}$ \\
\hline T value & & 0.665 & -3.408 & 0.152 & -4.723 & 0.215 & -3.721 \\
\hline P value & & 0.507 & 0.001 & 0.879 & $<0.001$ & 0.834 & $<0.001$ \\
\hline
\end{tabular}

Note: Compared with admission, ${ }^{a} P<0.05$

\section{Discussion}

Swanson's caring theory can help nurses keenly discover individual health needs and emotional changes, and give corresponding guidance from both physical and mental aspects to improve the effectiveness of education. Diabetes is a lifelong disease. Long-term illness and diet control are prone to sadness and helplessness. The proposed research has shown that emotional distress can prevent patients from exerting their abilities to perform appropriate self-management behaviors. Diabetes professionals should pay more attention to the emotional state of patients and its impact on self-care. This research combines the Swanson care theory with insulin injection education. In the process of educating patients with diabetes, nurses not only impart knowledge and nursing skills to patients, but also pay more attention to the patient's inner emotions and real needs, give them emotional support, help them overcome their emotional barriers, and establish confidence in controlling their illness.

At the same time, nurses intervene in advance for insulin addiction that most patients are afraid of, fear of self-injection, injections will take a lot of time and energy, etc., and grasp the key to the problem for in-depth communication so that patients agree with their beliefs, which eliminates the problem.

Insulin cognitive impairment allows the patient to truly understand and accept the treatment plan, and can also shorten the distance between the patient and the medical staff, and establish a good nurse-patient relationship.

In addition, the explanations and experience sharing of the patients' trusted clinical medical experts and those who have experienced insulin injections will enhance the patients' 
correct understanding of insulin therapy and increase the patient's confidence in mastering insulin injections.

The above measures have significantly improved the confidence of patients in insulin injection management, and patients can better perform insulin injections and self-care by various requirements in daily self-care, and ultimately control blood sugar. It can be seen that the Swanson care theory can guide to improve the self-care ability of patients, thereby achieving control of blood sugar and promoting patient health.

\section{References}

[1] Chakraborty, Partha Pratim, Biswas, Sugate Narayan, Patra, Shinjan, "Faulty Injection Technique: A Preventable But Often Overlooked Factor in Insulin Allergy,” Diabetes Therapy, vol.7, no.1, pp.163-167, (2016) DOI: 10.1007/s13300-016-0151-5

[2] Swanson, Kristen M., "Empirical Development of a middle range theory of caring," Nursing Research, vol.40, no.3, pp.161-165

[3] Swanson, Kristen M., "Nursing as Informed Caring for the Well-Being of Others," Journal of Nursing Scholarship, vol.25, no.4, pp.352-357 DOI: 10.1111/j.1547-5069.1993.tb00271.x

[4] Louise Schinckus, Florence Dangoisse, Stephan Van den Broucke, "When knowledge is not enough: Emotional distress and depression reduce the positive effects of health literacy on diabetes self-management," Patient Education and Counseling, vol.101, no.2, pp.324-330 (2018) DOI: 10.1016/j.pec.2017.08.006

[5] Chai Sanbao, Yao Baoting, Xu Lin, "The effect of diabetes self-management education on psychological status and blood glucose in newly diagnosed patients with diabetes type 2," Patient Education and Counseling, vol.101, no.8, pp.1427-1432 DOI: 10.1016/j.pec.2018.03.020

[6] Sun-Ju Kim. "Reduction of the Patient Hygiene Performance Index Based on an Oral Hygiene Program Using Oral Camera," International Journal of IT-based Public Health Management, vol.7, no.1, pp.9-14, (2020) DOI:10.21742/IJIPHM.2020.7.1.02

[7] DongSik Oh, "Gait Analysis in Adult People with Hip Retrotorsion," International Journal of IT-based Public Health Management, vol.6, no.2, pp.27-34, (2019) DOI:10.21742/IJIPHM.2019.6.2.05

[8] Song-hee Park, Bong-sil Choi, "Empathy, Self-Efficacy, and Nursing Performance of Nurses at Care Hospitals," International Journal of Advanced Nursing Education and Research, vol.5, no.1, pp.63-70, (2020), DOI:10.21742/IJANER.2020.5.1.08

[9] Nurul Ridhi Utami, Endang Mulyatiningsih, and Nurul Ridha Utami, "Recognizing Balanced Diets For Children," International Journal of Advanced Nursing Education and Research, vol.5, no.1, (2020), pp:7990,10.21742/IJANER.2020.5.1.10

[10] Jung-Ho Lee, "Therapeutic Intervention for Restoration of Sensory and Motor Function after Central Nervous System Injury," International Journal of Advanced Nursing Education and Research, vol.5, no.1, pp:31-36, (2020), DOI:10.21742/IJANER.2020.5.1.04 
Research on Improving Patients' Insulin Self-care Ability Based on Swanson Care Theory

This page is empty by intention. 